\title{
Informing action for United Nations SDG target 8.7 and interdependent SDGs: Examining modern slavery from space
}

\author{
Doreen S. Boyd (10 1,2凶${ }^{\text {}}$, Bertrand Perrat1,3, Xiaodong Li ${ }^{4}$, Bethany Jackson ${ }^{1,2}$, Todd Landman (1) 1,5, Feng Ling ${ }^{4}$, \\ Kevin Bales ${ }^{1,5}$, Austin Choi-Fitzpatrick ${ }^{1,6,7}$, James Goulding ${ }^{1,3}$, Stuart Marsh ${ }^{1,8} \&$ Giles M. Foody ${ }^{1,2}$
}

This article provides an example of the ways in which remote sensing, Earth observation, and machine learning can be deployed to provide the most up to date quantitative portrait of the South Asian 'Brick Belt', with a view to understanding the extent of the prevalence of modern slavery and exploitative labour. This analysis represents the first of its kind in estimating the spatiotemporal patterns in the Bull's Trench Kilns across the Brick Belt, as well as its connections with various UN Sustainable Development Goals (SDGs). With a principal focus on Sustainable Development Goal Target 8.7 regarding the effective measures to end modern slavery by 2030 , the article provides additional evidence on the intersections that exist between SDG 8.7 and those relating to urbanisation (SDG 11, 12), environmental degradation and pollution (SDG 3, 14, 15), and climate change (SDG 13). Our findings are then used to make a series of pragmatic suggestions for mitigating the most extreme SDG risks associated with brick production in ways that can improve human lives and human freedom.

\footnotetext{
${ }^{1}$ Rights Lab, University of Nottingham, Nottingham, UK. ${ }^{2}$ School of Geography, University of Nottingham, Nottingham, UK. ${ }^{3}$ N/Lab, Business School, University of Nottingham, Nottingham, UK. ${ }^{4}$ Innovation Academy for Precision Measurement Science and Technology, Chinese Academy of Sciences, Key Laboratory for Environment and Disaster Monitoring and Evaluation of Hubei Province, Wuhan, China. ${ }^{5}$ School of Politics and International Relations, University of Nottingham, Nottingham, UK. ${ }^{6}$ School of Sociology and Social Policy, University of Nottingham, Nottingham, UK. ${ }^{7}$ Kroc School of Peace, University of San Diego, San Diego, CA, USA. ${ }^{8}$ Nottingham Geospatial Institute, University of Nottingham, Nottingham, UK. ${ }^{凶}$ email: doreen. boyd@nottingham.ac.uk
} 


\section{Introduction}

n 2015, the United Nations articulated a set of 17 Sustainable Development Goals (SDGs), which are a newer and more comprehensive collection of development goals than the previous eight Millennium Development Goals (MDGs) established in 2005 (United Nations, 2016). As an 'indivisible whole,' the SDGs are seen to be an interdependent and mutually reinforcing set of actions to achieve a better and more sustainable future for all (Nilsson et al., 2016; Pradhan et al., 2017). With 10 years to achieve the more than 160 targets specified in the SDGs, it is important to evaluate progress and determine the many challenges that remain (Reyers and Selig, 2020). The task of achieving these targets is predicated on a large degree of visibility and significance for measurement and monitoring, where the provision of rigorous and systematic indicators are used for baseline and end-line assessments to understand overall progress. SDG Target 8.7 directly challenges the international community to take effective measures to end modern slavery and human trafficking (MSHT) by 2030, and presents a particular measurement challenge, owing to the nature of the 'hidden population' of those caught in various forms of MSHT. The many forms of exploitation that fall under the rubric of MSHT have significant intersections with a large number other SDGs, not least of which SDG Target 16.2 (end abuse, exploitation, trafficking and all forms of violence and torture against children) and SDG 5 (gender equality).

MSHT is extensive, diverse, and criminally pernicious (Bales, 2012; ILO, 2017; Tickler et al., 2018). It affects more people today than in any time in history (Walk Free, 2016) despite directly violating legal norms or laws in almost all countries across the globe (Schwarz and Allain, 2020). It takes many forms depending on the context in which it occurs, including debt bondage, domestic servitude, sexual exploitation, forced labour, forced marriage, and human trafficking, and it affects females disproportionally. In addition to SDG16 and SDG5, there is growing evidence (e.g., Brown et al., 2019; Decker Sparks et al., 2021) that some forms of MSHT, such as forced labour, human trafficking for labour purposes and child labour, have a strong bi-directional relationship with environmental degradation and climate change (i.e., SDGs 14 and 15), which in turn affects good health and wellbeing (SDG 3). Furthermore, the globalization of supply chains and global movement of poor, low-wage migrant workers-who are the most vulnerable to forced labour, modern slavery, and human trafficking-means that addressing SDG target 8.7 can bring benefits to many (SDG 12-responsible production and consumption). Failure to achieve SDG Target 8.7 potentially threatens sustainable development altogether (McGrath and Watson, 2018).

Better information on the extent of MSHT, including over time and space, is critical for its eradication. Current efforts to detect modern slavery rely on prevalence estimations using event-based data, standards-based data, and survey-based data (Landman, $2018,2020)$ that employ coding frameworks, counting rules, and inferential statistical approaches that draw on a variety of data sources at the local and national level (Silverman, 2020). Survey data underpin the most commonly quoted modern slavery prevalence estimate as part of the Global Slavery Index (GSI), which estimates that there were 40.3 million people living in slavery worldwide (Walk Free and International Labour Organisation, 2018) - an estimated 5.4 victims for every 1000 people in the world, with women and girls disproportionately represented. These approaches are highly valuable but have inherent limitations based on country selection and models of extrapolation (see Landman and Silverman, 2019; Landman, 2020). In order to redress some of these data limitations and to enhance the availability of methodological tools for measurement, we argue that efforts to address certain forms of slavery, i.e., forced labour, and any intersecting SDGs, can be advanced significantly with the use of satellite remote sensing data. This article presents the first ever spatiotemporal analysis of the geography of the Bull's Trench Brick Kilns (some of which are the fixed chimney type), herein called brick kilns, across the 1.5 million $\mathrm{km}^{2}$ 'Brick Belt' region of South Asia. We study these brick kilns as "objects of SDG intersectionality", where we do not measure slavery per se, but map the geographical distribution of physical sites (i.e., objects that are revealed in EO data), where there is a high probability of slavery prevalence. Revealing the geography of these sites (objects) also affords the study of their environmental and health impacts. This may then reveal intersectionality between the relevant SDGs.

By establishing the geography of these brick kilns in space and time, this paper undertakes a comprehensive assessment of a number of intersecting SDGs with which the brick kilns are associated. On the one hand, these brick kilns reflect a material risk to SDG 8.7 due to the reports of widespread and ongoing exploitation and abuse of workers in these brick kilns, the use of child labour, as well as situations of forced labour via debt bondage following trafficking (Bales, 2012; Kara, 2014; Khan et al., 2016). Debt bondage has been estimated to affect anywhere between $40 \%$ and $70 \%$ of the workforce used in these brick kilns (Mita and Valette, 2017; ASI, 2017; ILO, 2005; Save the Children, 2007). Current estimates of brick kiln numbers, underpinning slavery prevalence estimation, indicate the scale of exploitation that could be occurring: India alone houses between 60,000 (Budhwar et al., 2003) and 100,000 brick kilns (Rajarathnam et al., 2014); with 4\% annual expansion of the brick making industry (Khumbar et al., 2014). There are an estimated 500 brick kilns in Nepal (GEFONT, 2008), 5000 in Bangladesh-with 1000 around the city of Dhaka (Luby et al., 2015) - and 11,500 kilns in Pakistan (Mita and Valette, 2017). Unfortunately, these estimates suffer from three interconnected limitations: (1) they draw on different methods, (2) they occur at different census dates, and (3) they are not updated reliably. These drawbacks point to the importance of establishing a better baseline of both brick kiln numbers and their locations, as well as ancillary data, so that the scale of slavery within the brick production industry in this region might be better known. In addition to being sites of reported exploitation, these brick kilns also have a significant impact on the environment. The first phase of brick production involves the extraction of raw materials, such as water, topsoil, coal, wood and sand. The process of firing 'green' bricks releases significant and harmful emissions. Localised ground-surveys on the kilns illustrate that a range of pollutants and greenhouse gases are released and that these can often be worse in kilns using modern slavery, where low-grade materials are commonly used. Such emissions can lead to serious health implications for those working in or living near the kilns. Pollutants are not the only health concern. The heat generated by the kilns is also dangerous; as climate change affects the Brick Belt and days become hotter, there is an increased risk of heat-induced stress within the kilns (LundgrenKownacki et al., 2018); where, such impacts on outdoor workers are already evident elsewhere (Moda et al., 2019). These and other negative externalities associated with Brick Kilns illustrate why we argue for the interdependent approach to the SDGs and why our focus on SDG8.7 has important implications for realizing the other SDGs (https://www.developingfreedom.org/about/).

This article thus establishes a better baseline of both the number of brick kiln and their location so that the scale of slavery within the brick production industry in this region, along with its environmental impacts and health implications for workers (exploited or otherwise). Given the geographic scale of the Brick Belt, satellite remote sensing data and machine learning are 
suitable approaches to provide the first rigorous spatiotemporal mapping of the location of every brick kiln across the Brick Belt. Once mapped, we estimate the construction date of each brick kiln using the satellite record, affording an historical perspective that extends over a 30-year period. Our mapping expands the body of actionable intelligence about modern slavery over time and space. While the presence of brick kilns in our mapping may not directly relate to presence of workers, exploited or otherwise, the fact that there is a high likelihood of exploitative labour being used in a brick kiln means that it provides an initial and crucial piece of evidence to inform both public policy and anti-slavery activities. We use our spatiotemporal mapping to: (1) explore the relationship between supply and demand for the bricks manufactured in the kilns and understand the drivers for brick kiln installation, and (2) quantify how this industry, known to be underpinned by exploitative labour practices, has an impact on the environment. These analyses provide an unprecedented insight into the brick making industry across the Brick Belt and provide a benchmark to inform policy and guide action. We end by suggesting how remotely sensed data could be routinely used and help in a wider effort to secure the fundamental human right to freedom for those being exploited.

\section{Methods}

Study context. The brick kilns under investigation occur across the Brick Belt region of south Asia (a 1,551,997 km² region across Pakistan, Northern India, Nepal and Bangladesh). Known as sites where exploitative labour practices are common, these kilns spread across the Indo-Gangetic Plain, in one of the most reliedupon agricultural regions in the world and which supports $\sim 40 \%$ of the population of India. This area faces pressure from rapid urbanisation and population growth, variations in agricultural production, and environmental change, including climate change (Sapkota et al., 2015). The Brick Belt is home to the brick making industry, which underpins much of the infrastructure and economic development within the countries that comprise it (Hawksley and Pradesh, 2014). The most common form of kiln in which bonded labour is reported to be present, are Bull's Trench Kilns and the modified Fixed Chimney Bull's Trench Kilns (Maithel et al., 2014). These brick kilns are often highly polluting, yet they are economically appealing to owners, as operation costs can be up to $40 \%$ less than bricks produced using cleaner technologies (Luby et al., 2015). Previous work utilised fine spatial resolution satellite sensor data to produce the first statistically credible estimate of the total number of brick kilns contained in this Brick Belt region $[N=55,387$ (Min. $=44,542$; Max. $=66,270$ ) -(Boyd et al. 2018)]. This analysis also suggests that brick kilns are not uniformly distributed across the Brick Belt, with kiln density varying greatly across the region, and thus a blanket approach to spatiotemporal mapping and associated analyses with contiguous data (in space and time) is required (Foody et al., 2019). This demanded a satellite remote sensing for Earth observation (EO) approach, where we use data from a number of satellite EO systems, along with suitable ancillary data.

Spatiotemporal analysis-mapping of all brick kilns. These brick kiln installations have a distinct footprint and thus are identifiable in certain satellite remote sensing data (Foody et al., 2019; Nazir et al., 2020; Misra et al., 2020; Lee et al., 2021). The contiguous data for spatiotemporal mapping used very highresolution (VHR) satellite remote sensing imagery from Airbus Pléiades, an optical satellite constellation which acquires VHR data $(50 \mathrm{~cm}$ pixels) across four spectral wavebands (blue, green, red and near-infrared) within a $20 \mathrm{~km}$ swath (https://www. intelligence-airbusds.com/en/8692-pleiades). We employed full contiguous coverage across the Brick Belt of Pléiades imagery along with contemporary machine learning methods, which identify specific objects in images to map all brick kilns across the Brick Belt. Key features of brick kilns used as part of the machinelearning approach we adopt relate to their size and shape, as well as the presence of a central chimney that often casts a long shadow (Nazir et al., 2020). These features distinguish them from other objects that may show similarity, such as road roundabouts and abandoned kilns. Foody et al. (2019) established these distinguishing features in an earlier study. Specifically, we used a convolutional neural network (CNN) to detect every brick kiln present in the VHR Pléiades imagery covering the area of the Brick Belt. A CNN is a type of deep feedforward neural network, which has been found to be effective for the analysis of EO data (Long et al., 2017). The YOLOv3 CNN architecture is one of the fastest $\mathrm{CNN}$ architectures for object detection with an acceptable trade-off with detection accuracy (Yunong et al., 2019). Further, the YOLOv3 architecture was capable of processing the amount of VHR data in a timely manner, and could be repeatable in the future as a monitoring tool for newly established kilns.

We conducted an iterative three-step approach to training the YOLOv3 CNN. First, we ran an initial object detection using a training set collected previously by Boyd et al. (2018). This training set comprised a thousand examples of kilns that had successfully been annotated by volunteers via the online citizen science platform Zooniverse. The crowd-annotated kilns only covered a $120 \mathrm{~km}^{2}$ region in Rajasthan, India, nonetheless the resultant $\mathrm{CNN}$ model was used to detect kilns across the entirety of the Brick Belt to generate an output map which fed into the second stage. This second stage produced a refined training set from which we randomly selected 3000 detected kilns from across the Brick Belt and then manually reviewed by visual interpretation by an expert (as per Boyd et al., 2018) a square of $2 \times 2 \mathrm{~km}$ centred on each selected kiln for false positives and false negatives. This process afforded a training set of 2709 kilns, which overcomes the spatial limitations of the crowdsourced annotations and where we considered examples of brick kilns from across the entirety of the Brick Belt. Thus, we were able to model any spatial variation in the kiln structure and locational context (urban vs. rural). The third and final stage involved using the refined training set (2209, with 500 kilns held back for validation to inform the early stopping of the training) to retrain the CNN with a network size of $608 \times 608$. The network was trained for over $24 \mathrm{~h}$ and over 20,000 epochs (i.e., runs through the network).

In order to process the whole Brick Belt with the trained CNN model, we imposed a grid of $50 \mathrm{~km}$ squares on the Brick Belt extent, resulting in 893 total cells. This afforded ease in monitoring the processing process. We then processed each cell of the grid iteratively with the CNN to detect the brick kilns in the satellite data. We then divided each $50 \mathrm{~km}$ zone into small patches $\left(1 \mathrm{~km}^{2}\right)$ to be passed through the CNN for prediction. To overcome the issue of brick kilns potentially located on the edge of two patches, we introduced an overlap between patches. The selection of this overlap was large enough to make sure a kiln would be seen entirely in at least one of the patches, even if it was located at the frontier of two patches. We removed any multiple, overlapping predictions and geospatial operators used to filter and merge the predictions based on a set of criteria. We stored the generated results in a PostGIS database listing every kiln across the Brick Belt. Through this process, we were able to map a total of 66,455 brick kilns with an overall accuracy of $92.83 \%$. An image interpretation expert calculated this through visual comparison of the mapping against the imagery-as per Boyd et al. (2018) and Foody et al. (2019) each sampled region was labelled as kiln or non-kiln. The quality of each of the brick kiln mappings obtained was estimated using standard measures of accuracy, which revealed a model precision of $98 \%$ and recall of $87 \%$. 

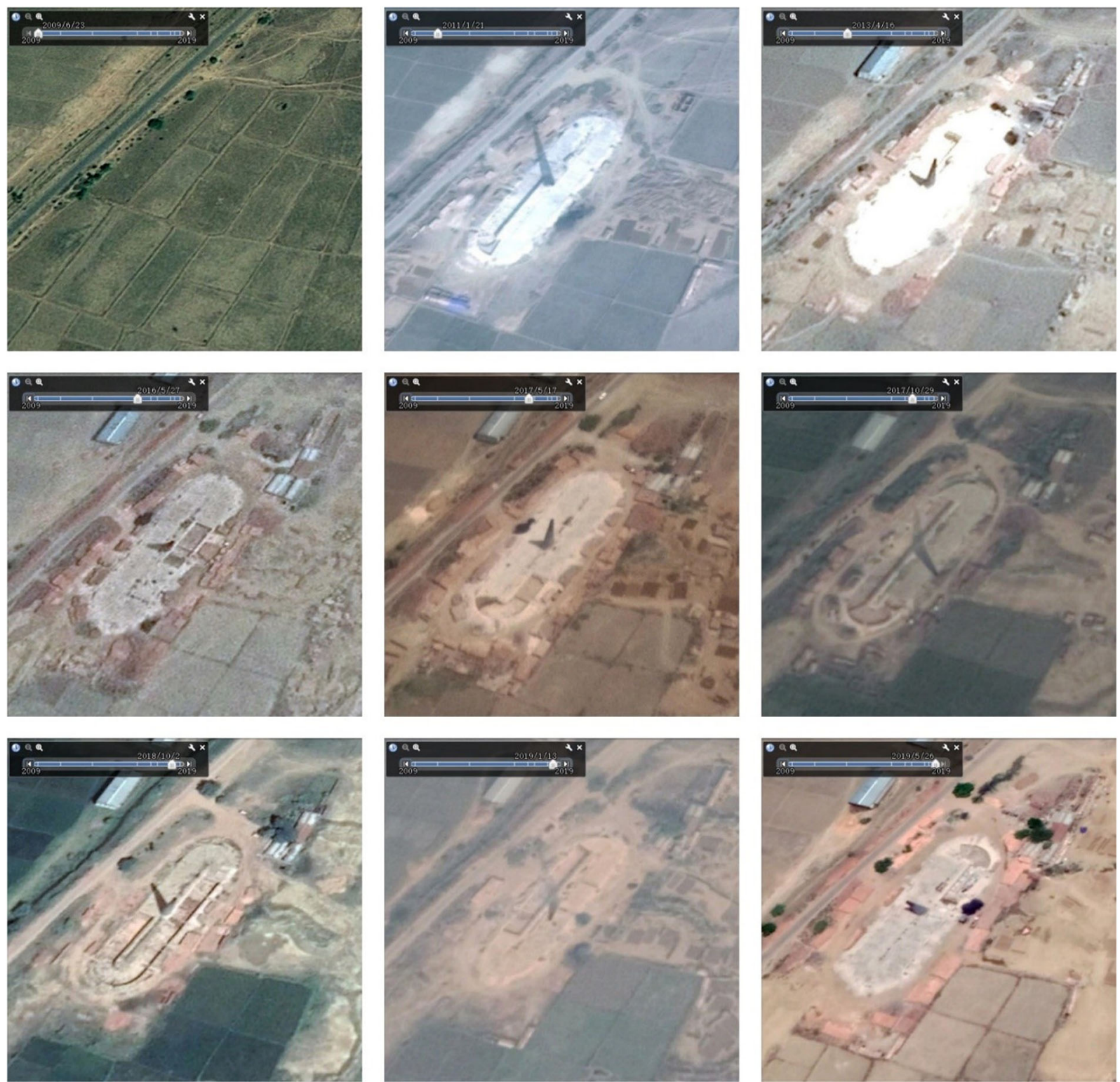

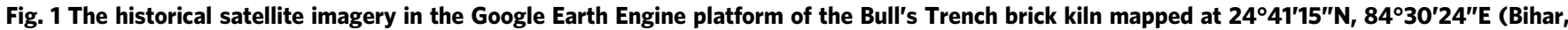
India). Data from Google, (c) 2021, CNES/Alrbus, Maxar Technologies. This kiln has not been built in the earliest image of this location (acquired on June 23, 2009), but had been built by the time the image dated January 21, 2011 was acquired; this kiln was inferred to be built between these two dates. The rest of the images illustrate how the same kiln appears throughout the satellite record in Google Earth, through to the latest date-26 May 2019 . Note that the temporal frequency of kiln capture increases over time as the use of VHR satellite imagery becomes more common place.

Spatiotemporal analyses-dating construction of brick kilns. The date of construction of each of the 66,455 brick kilns was estimated from the USGS Landsat satellite time series record (https://landsat.usgs.gov/usgs-landsat-global-archive) by way of a random forest (RF) classifier (Breiman, 2001). We used data acquired by the Landsat 5 Thematic Mapper (TM), Landsat 7 Enhanced Thematic Mapper (ETM+) and Landsat 8 Operational Land Imager (OLI), over a 30-year period between 1988 and 2018. All Landsat data are calibrated to surface reflectance and any data with cloud and shadow excluded based on the CFmask (Zhu and Woodcock, 2012). We used five spectral bands for our analysis: (1) green, (2) red, (3) near infrared, (4) shortwave infrared 1, and (5) shortwave infrared 2. A key characteristic of this Landsat time series is its long history but also its dense temporal repetition rates (nominally semi-monthly) and high spatial resolution (nominally $30 \mathrm{~m}$ ) over the whole of the chronology. This was important for attaining high accuracy estimation of construction date of each kiln.

As there were no ground data to train the classifier (and validate), we conducted a visual inspection of the VHR satellite data available through the Google Earth Engine (GEE) platform (e.g., WorldView, Pléiades, GeoEye-1, and QuickBird) since the year 2000 (https://earthengine.google.com/platform). The distinctive shape of the kilns allows for visual interpretation and supports the Landsat time series data in the estimation of kilns' construction date. The earliest VHR images were viewed for each of the mapped kilns to determine kiln presence/absence (see Fig. 1 for an example). Kiln presence was denoted $t_{1}^{\mathrm{G}}$ (see Table 1 for all notations), with the date of kiln construction inferred to be prior to $t_{1}^{\mathrm{G}}$. Kiln absence meant all temporally subsequent 


\section{Table 1 Notations used in the spatiotemporal estimation of the date each of the brick kilns were constructed.}

\section{Variable name Definition}

th the start date of Landsat data used in aging a kiln; for each kiln, $t_{0}^{\mathrm{L}}$ is set to the earliest Landsat 5 TM data according to the kiln's coordinates, which is usually from the year1988 in the South Asian countries in the analysis the end date of Landsat data used in aging a kiln; $t_{\text {end }}^{L}$ is set to December 31, 2018 for all kilns the date that the kiln was first observed in Google Earth the date of the closest Google Earth image before $t_{1}^{G} ; t_{0}^{G}$ is identified only when the kiln has not been built in the earliest Google Earth image according to the kiln's coordinates
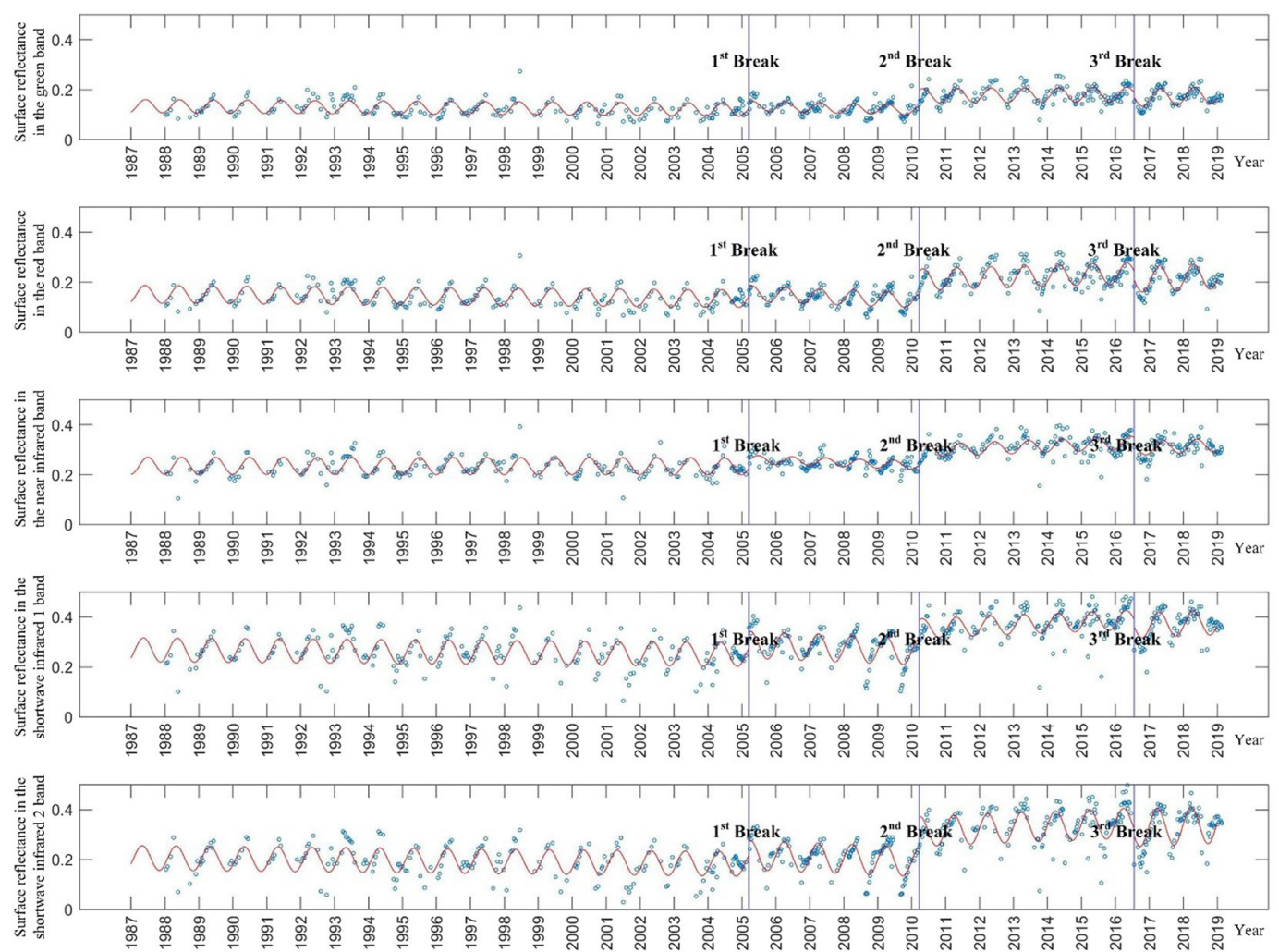

Fig. 2 The break point detection of a Landsat time series in five bands in determining when the Bull's Trench brick kiln-24 ${ }^{\circ} \mathbf{4 1}^{\prime} 15^{\prime \prime} \mathrm{N}, \mathbf{8 4}^{\circ} 30^{\prime} 24^{\prime \prime} \mathrm{E}-$ was constructed in Bihar, India. The blue circles represent the surface reflectance values, and the red curves represent the fitted time series functions.

imagery in GEE were visually inspected with the date at which the kiln was first observed denoted as $t_{1}^{\mathrm{G}}$, and the date of the closest VHR image before $t_{1}^{\mathrm{G}}$ defined as $t_{0}^{\mathrm{G}}$. The kiln in question is inferred to have been constructed between $t_{0}^{\mathrm{G}}$ to $t_{1}^{\mathrm{G}}$ but an exact year could not be ascertained since VHR data for the Brick Belt is not collected routinely across space and time.

Thereafter, the detection of a break (i.e., change) point in the Landsat time series data for each of the mapped kilns was used to predict the probability that a kiln has been constructed. Using the Landsat data surmounts the issue of temporal and spatial infrequency seen with VHR data on GEE, it also has a longer temporal record. For each mapped kiln, the start date in the Landsat analysis, i.e. $t_{0}^{\mathrm{L}}$, was set to the earliest Landsat image (most often 1988, from Landsat-5 TM) and the end date, i.e. $t_{\text {end }}^{\mathrm{L}}$, set to December 31, 2018 (Landsat-8 OLI). Thus, a Landsat time series data from $t_{0}^{\mathrm{L}}$ to $t_{\text {end }}^{\mathrm{L}}$ with five spectral bands was used with the assumption that the construction of a kiln would break the linear trend and the seasonal or intra-annual variation in the reflectance values. A so-called 'break point' occurs when a significant change in the mean and where the slope and standard deviation on either side of a data point in each of the Landsat spectral bands is present. The break point detection identifies abrupt changes in these statistical values along the Landsat time series data while minimizing the total residual error (Verbesselt et al., 2012). Figure 2 illustrates the Landsat time series in the five spectral bands for the same kiln in Bihar, India identified in Fig. 1 where three breaks were detected.

Although any 'break-point' in the Landsat time series has a high probability of resulting from kiln construction, it could also indicate other land use changes and so the RF classifier was used to identify the particular 'break points' resulting from the construction of a kiln. The kilns detected visually on the VHR data on GEE as being constructed between $t_{0}^{\mathrm{G}}$ and $t_{1}^{\mathrm{G}}$ were used as training and validation sets. Of the 66,455 kilns, 30,483 were constructed between the dates $t_{0}^{\mathrm{G}}$ and $t_{1}^{\mathrm{G}}$, and were randomly divided into two groups, with 15,408 kilns (10,389 kilns in India, 1981 kilns in Bangladesh, 2565 kilns in Pakistan, and 473 kilns in Nepal) used as training data to train the classifier, and the other 15,075 kilns (10,167 kilns in India, 1960 kilns in Bangladesh, 2468 kilns in Pakistan, and 480 kilns in Nepal) used for validation. 
In the training stage of the RF classification, all the breaks in the Landsat time series for each of the 15,408 kilns in the training set were identified as either being a 'true break' if the break occurred between $t_{0}^{\mathrm{G}}$ to $t_{1}^{\mathrm{G}}$ or a 'false break' otherwise. The inputs to the classifier included the 30 features calculated by the subtraction function for each break and the label of 'true break' or 'false break' of that break. Executing the RF classifier on the Landsat time series for each of the mapped kilns afforded a prediction of the probability of each break in time series being construction date for that kiln. By comparing the probability of the break with a threshold, candidate break(s) were selected to represent the construction date of the kiln if the probability was higher than the threshold. If no break was detected in the Landsat time series data then the kiln was inferred to be built before the earliest Landsat date $t_{0}^{\mathrm{L}}$ (1988). The threshold value is important, especially for the kilns where the date $t_{0}^{\mathrm{G}}$ cannot be visually identified from GEE to refine the Landsat predictions. If the threshold is relatively high, then there will be an omission error in aging kilns where the date $t_{0}^{\mathrm{G}}$ cannot be visually identified. In contrast, if the threshold is relatively low, the breaks caused by different land cover transitions would be predicted as the kiln's construction for kilns which the date $t_{0}^{\mathrm{G}}$ cannot be visually identified. The optimal value threshold value was determined based on all the breaks from $t_{0}^{\mathrm{L}}$ to $t_{\text {end }}^{\mathrm{L}}$ using all the 15,408 kilns from the training data by trial and error. The threshold value that generated the highest percentage of correctly predicted breaks using all the breaks from the 15,408 training samples was used to determine the date of construction of all the mapped kilns.

The validation set $(15,075$ kilns) was used to determine the mean difference in time between the predicted date of construction and testing set. Since a kiln's construction may be continued for a period of time using an exact Julian date to denote when it was constructed may be improper, thus we assumed the prediction date was correct if it was in the period from $\left(t_{0}^{\mathrm{G}}-365 / 2\right.$ days $)$ to $\left(t_{1}^{\mathrm{G}}+365 / 2\right.$ days $)$. If no break was detected for a kiln then this kiln was not accounted for in computing the mean difference. From this it was evident that the mean difference between the predicted date and $t_{0}^{\mathrm{G}}$ was 1.83 years, and $t_{1}^{\mathrm{G}}$ was -1.55 years.

Exploring the relationship between supply and demand for bricks. Given the lack of suitable temporal update via official census records of population demographics, we used the National Oceanographic and Atmospheric Administration (NOAA) Night-Time Lights (NTL) time series (https://ngdc.noaa.gov/eog/ dmsp/downloadV4composites.html) data, which are based on data acquired by the Defense Meteorological Satellite Program (DMSP) Operational Linescan System (OLS). Specifically, the NTL product, avg_lights_x_pct, is derived from the average visible band digital number (DN) of cloud-free light detections multiplied by the percent frequency of light detection at a resolution of 30 arc-second grids. This product has been used as a proxy for socio-economic and demographic variables, including urban density, population size, economic status, and the provision of public goods (Mellander et al., 2015; Xiao et al., 2014; Min, 2015; Hall et al., 2019). The use of NTL data as a proxy variable is based upon there being a direct or an indirect link between the sources of NTL and the variable of interest. Here the NTL data were used as a proxy for annual population growth across the Brick Belt for an 18-year period (1996-2013 inclusive as determined by data availability). The total measure of NTL (i.e., avg_lights_x_pct) from across the Brick Belt was computed for each year between 1988 and 2013. Likewise, for the number of kilns constructed per year. We computed a statistical measure of the relationship (Pearson's $r$ ) between annual cumulative numbers for both kilns (i.e., supply) and NTL, as a proxy for population growth, (i.e., demand).

Environmental impact assessment of the brick kilns. We used landcover maps to quantify resource extraction by the kilns between the years 2001 and 2017. We specifically used Layer 1 of the Landcover product from the Moderate Resolution Imaging Spectroradiometer (MODIS) sensor (Earth Resources Observation and Science (EROS) Center; part of the MCD12Q2 Collection 6 Product-Land Cover \& Surface Climate Group, n.d.; Gray et al., 2019; Sulla-Menashe and Friedl, 2018). This schema contains 17 unique landcover classes known as the International Geosphere-Biosphere Programme (IGBP) classification (Loveland and Belward, 1997), including 14 vegetation classes, 11 natural and three human-altered, as well as three non-vegetated classes which includes water bodies (Sulla-Menashe and Friedl, 2018 , p. 7). These data are the latest, improved MODIS landcover maps (see Friedl et al., 2002; Ganguly et al., 2010). We downloaded six tiles of the landcover map for each year to provide fullspatial coverage of the Belt, which were intersected with the kiln construction date data for each year to determine the landcover classes impacted and the rate at which this has changed over time. Topsoil is one of the two primary resources required during brick manufacturing. The number of bricks produced is estimated to be between 2 and 3.5 million per kiln per year (Gomes and Hossain, 2003; Guttikunda et al., 2013; Saeed, 2017). The lower estimate was used to determine the total number of bricks produced across the Brick Belt before applying to known levels of topsoil extracted by kilns within India: equating to 400 million tonnes of topsoil each year (Lopez et al., 2012: 10; Mitra and Valette, 2017, p. 22). These figures were extrapolated to estimate the total topsoil extracted across the region.

A similar analysis was used to determine approximately how much groundwater is used by the kilns; he other primary brickmaking resource. Figures from research by Shrestha et al. (2013, p. 3) found $0.75 \mathrm{l}$ of groundwater are used in the production of a brick,which is comparable to $0.6-0.81$ of all water sources (Kumbhar et al., 2014). We applied the Shrestha et al. (2013) figures across the region determining an estimate of the scale of resource extraction required to manufacture the bricks in the Belt. We also assessed kiln proximity to water sources as this has an impact on pollutant levels entering the water supply. We computed five $1 \mathrm{~km}$ buffers for each river or water body (such as a lake or reservoir) and intersected these with kilns to determine the number located within this distance. We also noted kilns found within the riverbed, which is an issue previously addressed in Uttarakhand and Bihar (India) as the kilns can affect natural flood protections (Economic Times, 2013; Gupta, 2015).

PM2.5 is the principal air pollutant that directly impacts on the health of kiln workers, and indeed the general population living nearby (Nepal et al., 2019). We used the Global Annual PM2.5 data (micrograms per cubic meter $\left(\mu \mathrm{g} / \mathrm{m}^{3}\right)$ of ground-level fine particulate matter, with dust and sea-salt removed) from MODIS, MISR and SeaWiFS Aerosol Optical Depth (AOD) with GWR, v1 (1998-2016) with a spatial resolution of 0.01 degree (https:// sedac.ciesin.columbia.edu/data/set/sdei-global-annual-gwr-pm25-modis-misr-seawifs-aod). For 4 epochs of time (2000, 2005, 2010, and 2015) the data are mapped for the Brick Belt as a whole. A more micro-level analyses on PM2.5 associated with brick kiln was undertaken for those urban areas having the largest number of kilns across the four countries. For each of these areas, the city boundaries as determined by GADM data (version 3.6) which maps the administrative areas of all countries, at all levels of sub-division (https://gadm.org/download_country_v3.html) were used to determine the number of kilns present for the 
period 1998-2016, and this was plotted against the spatially corresponding annual concentrations of PM2.5 $\left(\mu \mathrm{g} / \mathrm{m}^{3}\right)$.

\section{Results and analyses}

Spatiotemporal mapping. We provide the first rigorous mapping of the location of every brick kiln across the Brick Belt of South Asia. At the sampling epoch of 2018, our mapping (Fig. 3) revealed a total 66,455 brick kiln structures. Of these: $69.7 \%$ $(46,319)$ are in India; $17.3 \%(11,497)$ in Pakistan; $11.3 \%$ (7509) in Bangladesh; $1.7 \%$ (1130) in Nepal. Coupled with any ground intelligence of exploitation numbers within a brick kiln this mapping provides a step-change in prevalence estimation for modern slavery in this industry in this area. In addition to knowing the location of each kiln, our spatiotemporal analysis, which maps all new kilns constructed year-on-year (Fig. 4), reveals a growing industry since our 1988 baseline. This growth has occurred at different rates across time and space. In the absence of direct observations of slavery, these estimates provide

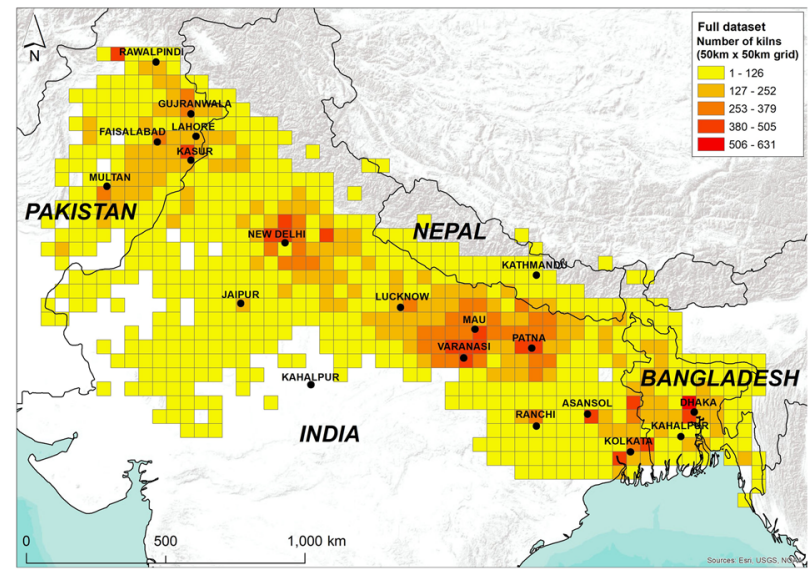

Fig. 3 First rigorous mapping of all Bull's Trench brick kilns as at 2018 presented as density (number of kilns per $50 \times 50 \mathrm{~km}$ square) across the 1.5 million km² $^{2}$ so-called 'Brick Belt' region (includes Pakistan, northern India, Nepal and Bangladesh). In total 66,455 brick kilns were identified from the satellite data and mapped. a proxy measure for prevalence and also slavery vulnerability across this vast area.

The relationship between supply and demand for bricks. Our spatiotemporal data on brick kiln construction dates also affords some insight into what is driving the need for bricks and in turn, the labour force to work in the brick kilns. We hypothesize that this is the product of urban demand for cheap construction material, which itself generates competitive price environments that also exert a downward pressure on wages. In the absence of political will or countervailing social norms, this downward pressure on wages extends to the denial of wages altogether (Choi-Fitzpatrick, 2017). There is support for this hypothesisalthough suitable clay is everywhere across the Brick Belt for making bricks (MWFP EPA, 2004), kilns are geographically correlated with urban settlement centres (Figs. 3 and 4) and, in general, the highest concentration of kilns are in close proximity to the largest urban centres and their infrastructure networks. India's largest concentration of kilns can be found around Delhi, Varanasi, Patna and Asansal; Pakistan's around Lahore, Multan and Gujranwala; Bangladesh's around Dhaka and Nepal's around Kathmandu and Kahalpur. The close proximity of kilns to urban settlements indicates that the supply chains for these brick are local. Further support for this local supply and demand dynamic is evident in our correlation analysis (see the "Methods" section). As is evident in Fig. 5, a strong positive correlation $(r=0.84, p<$ 0.001 ) exists between population growth (the satellite-captured night-time lights used as a proxy) and the cumulative increase in kilns in the region over an 18-year period. This suggests that as long as there remains such a strong demand for bricks, then the risk of slavery in the region also remains (Mitra and Valette, 2015; Shah, 2006).

Assessing environmental impact. Around $80 \%$ of the mapped kilns are located on land classified as 'cropland' (Table 2). Whilst 'cropland' covers the largest proportion of landcover in the region (an area between $930,000 \mathrm{~km}^{2}$ in 2001 and almost 980,000 km $\mathrm{km}^{2}$ in 2017 with some fluctuation), the number of kilns found within this region is not proportionately distributed, skewing toward formation on agricultural lands. This tallies with the need for strong and fertile topsoil to produce bricks and as such the rise in the number of kilns within the Brick Belt has led to an increase in

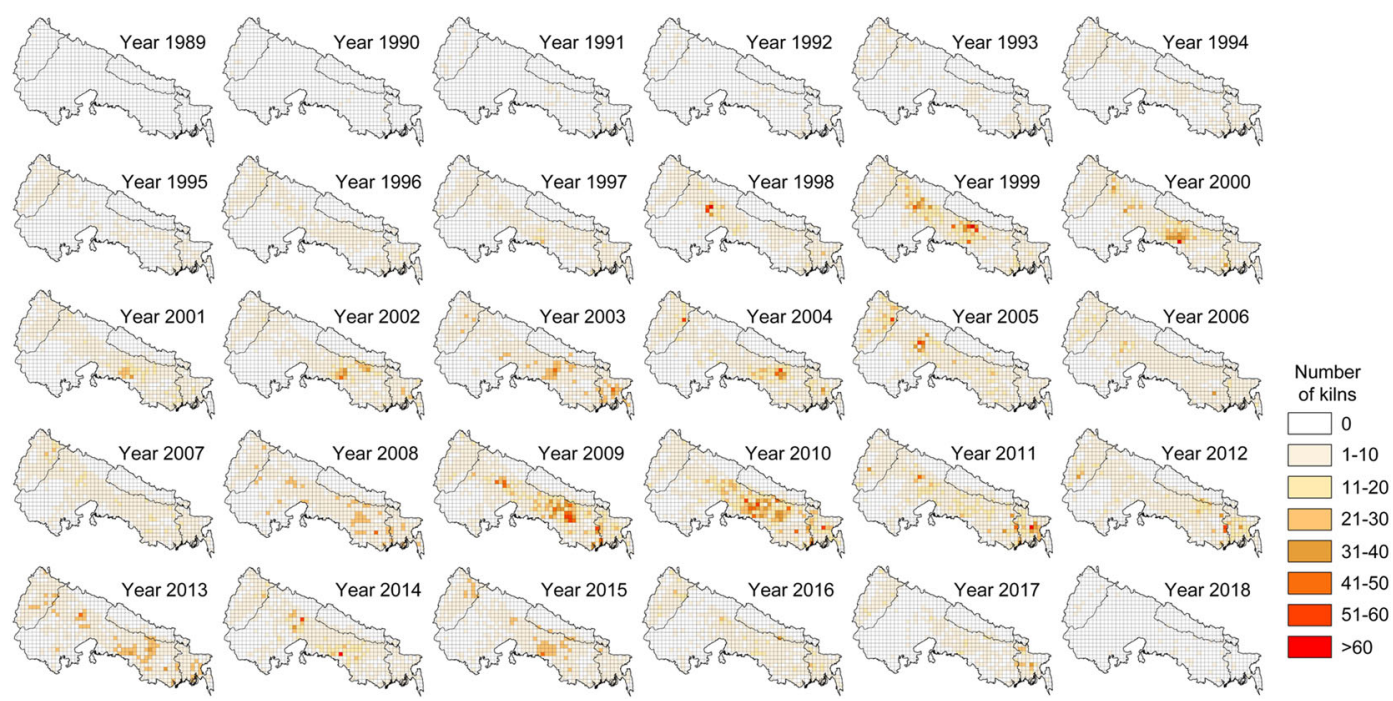

Fig. 4 Mapping of the density of Bull's Trench brick kilns (number of kilns per $\mathbf{5 0} \times \mathbf{5 0} \mathbf{~ k m}^{\mathbf{2}}$ ) constructed annually. Each map illustrates the number of brick kilns established in a year (from 1989 through to 2018, with the number of kilns in each $50 \times 50 \mathrm{~km}^{2}$ area depicted by the key. 


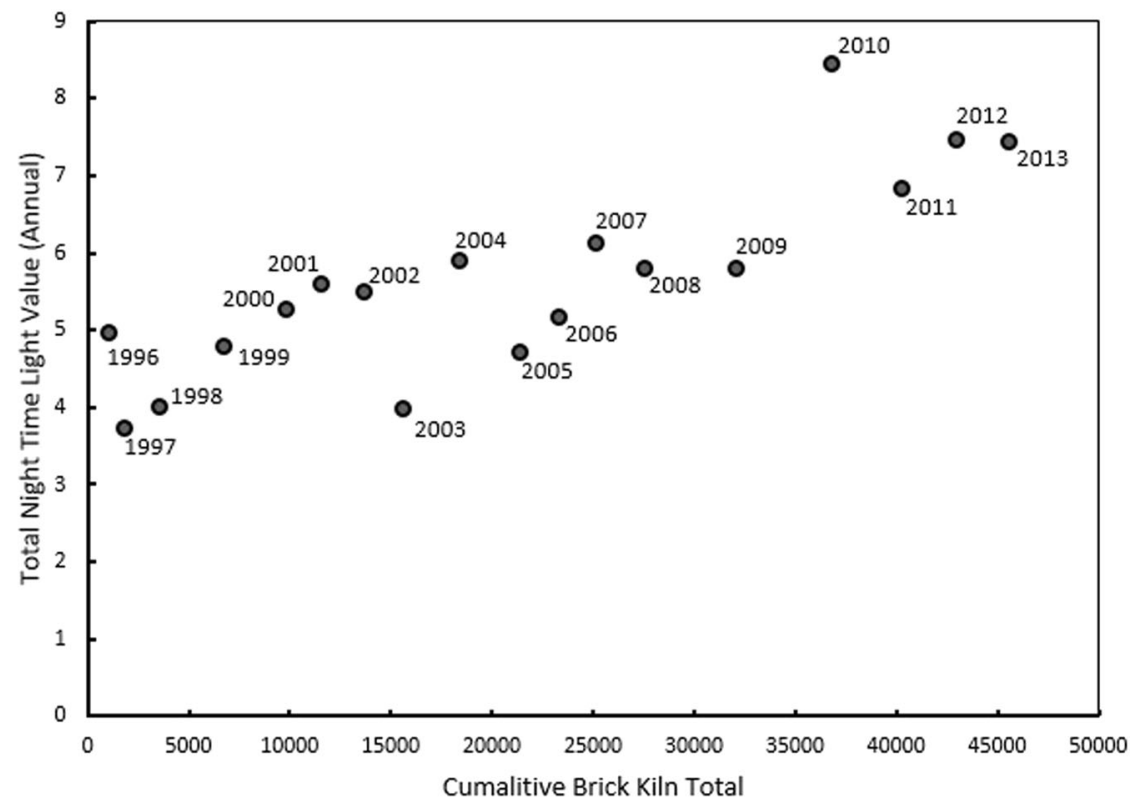

Fig. 5 Plot of relationship between population growth (DMSP Operational Linescan System (OLS) satellite-captured night-time lights data used as a proxy) and the cumulative increase in the number of newly constructed Bull's Trench brick kilns across the Brick Belt region. Note that each data point is denoted by its year.

the extraction of topsoil (Fig. 6), totaling an estimated 266 million metric tonnes in 2018.

Water extraction has also increased as a result of the growing number of kilns built over time (Fig. 6). Using the estimated 0.751 of groundwater per brick required during production according to Shrestha et al. $(2013$, p. 3) gives an estimated 150,0001 of groundwater use per kiln per year. Thus, during 2018 a total of 101.64 billion litres of groundwater were used across the Brick Belt. Further impact of the kilns on water resources in the region is illustrated with the proximity analysis of all kilns and water sources, which showed that the vast majority are found within $5 \mathrm{~km}$ of a river, canal, lake or reservoir (Table 3). A number of these kilns were also located within the river channel (including the floodplain), subjecting them to extensive and rapidly intensifying flood events particularly during the monsoon (Loo et al., 2015). Flows are also enhanced by Himalayan glacial melt into rivers including the Indus and Ganges (Lutz et al., 2014; Sadoff et al., 2013).

The PM2.5 concentrations have increased over the period between 1998 and 2016 across the Brick Belt (Fig. 7). The spatial pattern in emissions follows the main urban centres, with the highest concentration of PM2.5 emission seen in the vicinity of Dehli, India. A focus on each of the main urban centres for each country in the Brick Belt reveals a similar trend-an increase in PM2.5 over time, which is associated with an increase in Brick Kiln numbers (Fig. 8). Although other land use practices will also lead to emissions of PM2.5 across the Brick Belt, it should be noted that it has been observed that kilns that use environmentally damaging fuel, which emit a range of pollutants including PM2.5 do have a higher chance for the occurrence of illegal working practices (Bales, 2012, pp. 109-110).

\section{Discussion and conclusions}

This article has shown that the use of satellite EO data, of different resolutions from different systems, sheds unprecedented light on the brick kiln industry of south Asia-an industry and area that has been reported to use a high prevalence of bonded labour. While our spatiotemporal analysis does not measure slavery per se, it does establish an updatable baseline for the sites, which we term "objects of SDG intersectionality" where exploitation is known to occur. In the absence of direct observations of slavery, our analysis provides a proxy to prevalence, but also to vulnerability, across this vast area. While the presence of brick kilns in our mapping may not directly relate to presence of workers, subjected to modern slavery or otherwise, the fact that there is a high likelihood of bonded labour being used in a brick kiln means that our mapping provides an initial and crucial piece of evidence to inform both public policy and anti-slavery activities. Our spatiotemporal analysis of brick kiln construction dates also affords some insight into what is driving the need for bricks and, in turn, the labour force to work in the brick kilns. In this way, we advance humanitarian objectives as well as provide a foundation dataset regarding a key industry in the region. It is our hope that this dataset helps policy makers set policy and help NGOs to undertake carefully designed interventions to address any concerns around exploitative labour practices.

The methods presented here and the intelligence they provide are imminently suitable for triangulation with existing efforts of measurement of modern slavery that rely on events, standards, and survey-based data for the measurement of individual cases of slavery. This triangulation should afford an insight into the nature of MSHT, in addition to its extent. Knowing where to focus resources on the ground optimises antislavery, and its associated, efforts. Our ongoing work with the United Nations Development Programme's (UNDP's) India Accelerator Lab, is an example of this in action. The spatiotemporal mapping of the brick kilns underpins a mobile app that guides NGOs and intragovernmental organisations in India; to aid their understanding of the scale and location of the industry and therefore their action in the form of community prevention, liberations, inspection and regulation, as well as their work around reducing air pollution (https:// acceleratorlabs.undp.org/content/acceleratorlabs/en/home/library/ fast-and-curious-our-story-so-far-2019-UNDP-accelerator-labsannual-report.html). The data captured in this way affords also affords the examination of the interdependent and mutually reinforcing relationships that exist between and among different SDGs. 


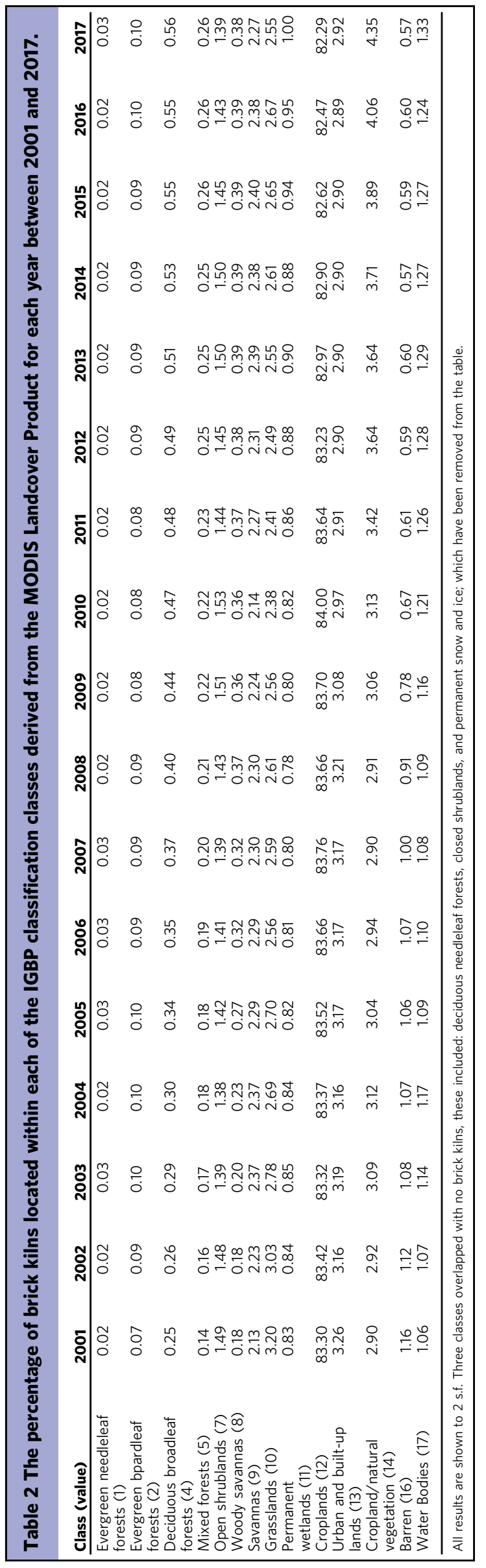

Our supply and demand analysis indicates that as things currently stand population increases are associated with increases in the number of kilns, suggesting that continued demand for bricks increases the risk of slavery for the region (Mitra and Valette, 2017; Shah, 2006). Aligned with this would be a subsequent increase in resource extraction and emissions from the brick manufacturing industry (Natarajan et al., 2019). Again, we hope that the quantification provided here of these environmental impacts assists in the targeted action surrounding the manufacturing practices in the kilns and provide the baseline data to measure progress towards a lower impact industry. Whilst these environmental estimates may not be as nuanced as one may hope at present due to the lack of disaggregation in the types of kilns, there are actions in place that can assist with differentiating these environmental impacts being promoted by the UNDP (Agrawak, 2020). These data can assist in tailoring the baseline estimates from this study and support combined social-ecological actions to achieve SDG targets. Furthermore, where evidence from smaller-scale investigations have been collected for example to differentiate between active and abandoned kilns (Misra et al., 2020), these techniques should be utilized in order to refine these environmental baseline estimates and be used to update current algorithms to identify those differences between the Bull's Trench Kilns and those converted to use cleaner technologies; thus providing ongoing and more accurate usage of topsoil, groundwater, and pollutant releases. What is clear is that whilst these assessments can be supported by satellite EO data, there should be a conscious effort to work with organisations to collect ground-data that establish spatiotemporal monitoring systems moving forward.

The implications of current brick manufacturing practices across the Brick Belt using these traditional brick kilns include, reduced access to water for agriculture, cleaning, sanitation and food preparation and depleted top soil resource for agriculture and food security. This is a direct threat to sustainable agriculture practices (Biswas et al., 2018), as well as an increase in the potential likelihood of agricultural shocks linked to livelihood precariousness in the region (Berchoux et al., 2019). In addition to the conversion of agricultural land into clay fields, we show that the brick kilns occupy agricultural land in almost $80 \%$ of cases; land which becomes unsuitable for food production once degradation by the kilns has occurred. This is likely to fuel the further selling of soil for small-scale and subsistence farmers and further reduce crop production. Biswas et al. (2018) note that in Bangladesh this is becoming an issue with farmers reporting $40-80 \%$ crop yield reductions and lowering of income by up to $70 \%$. This has a knock-on effect of pushing migration to the kilns, increasing population density around the kilns, and fueling the problem of modern slavery and exploitative labour practices.

The brick kilns in this region are also contributing to the pollution levels in one of the fastest developing regions in the world. Our analysis cannot determine that the brick kilns are the primary contributor to pollution; however, the aligned increase in kilns and emissions of PM2.5 indicate that improvements and lowering emissions from the brick manufacturing sector are necessary to protect human and environmental health. Interventions to limit kiln emissions have been explored in the region (Begum et al., 2011; Darain et al., 2013; Larsen, 2016). Here, there has been a push toward more sustainable manufacturing whilst limiting costs. Cost is an important factor in the changing behaviour of brick kiln owners, particularly as competition can be high; there is an overwhelming use of debt bondage labour to reduce prices. Further, by shining a light on the kilns' need to adopt cleaner technology, their governance is improved which should have a secondary benefit of revealing labour conditions. Bull's Trench Kilns and Fixed Chimney Bull's Trench can be 


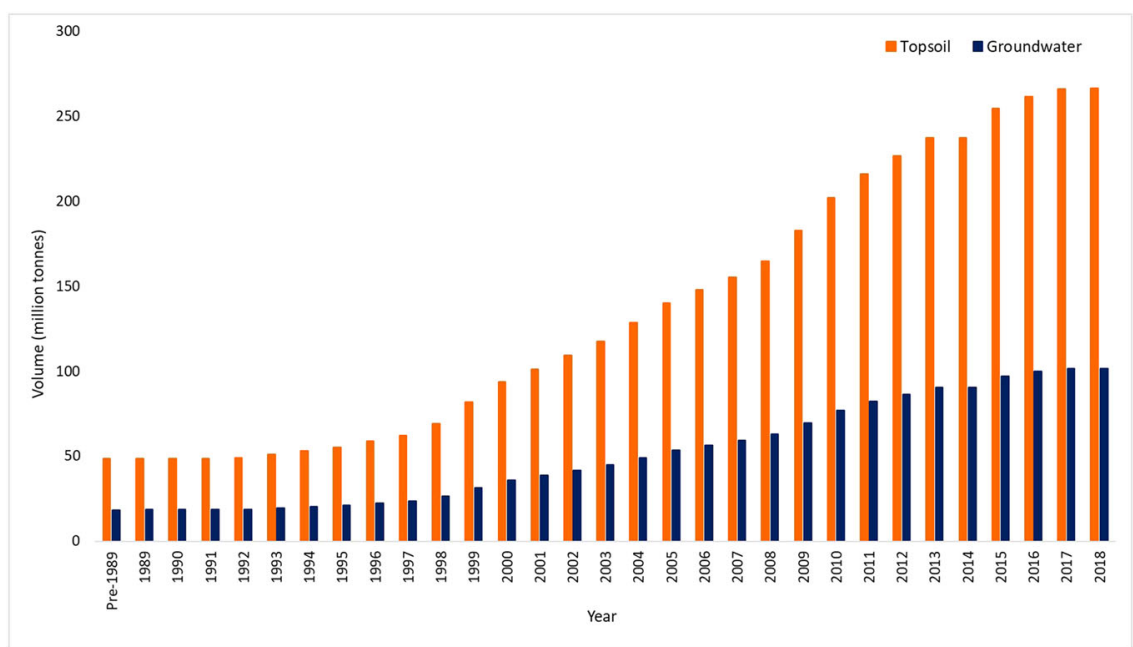

Fig. 6 Total estimates of topsoil and groundwater extraction in metric tonnes per year of assessment. Topsoil estimates are shown in red and groundwater extraction in blue.

Table 3 Proximity buffers from water bodies across the 'Brick Belt' to brick kilns in 2018 identified during the CNN-YOLO mapping process for the cumulative dataset.

\begin{tabular}{|llllr}
$\begin{array}{l}\text { Distance }(\mathbf{k m}) \\
\text { (buffer) }\end{array}$ & Small rivers/canals (only) & $\begin{array}{l}\text { Major rivers, lakes and } \\
\text { reservoirs }\end{array}$ & $\begin{array}{l}\text { All water bodies } \\
\text { combined }\end{array}$ & $\begin{array}{l}\text { Percentage of kilns per buffer } \\
\text { (all water) }\end{array}$ \\
\hline$<1$ (in river channel) & - & 846 & 846 & 1.27 \\
1 & 17,883 & 3526 & 19,559 & 29.35 \\
2 & 16,967 & 3772 & 15,899 & 23.86 \\
3 & 12,313 & 4498 & 11,249 & 16.88 \\
4 & 8391 & 4547 & 7515 & 11.28 \\
5 & 5403 & 4326 & 4366 & 6.55 \\
$>5$ & 4837 & 44,279 & 6360 & 9.54 \\
\hline
\end{tabular}
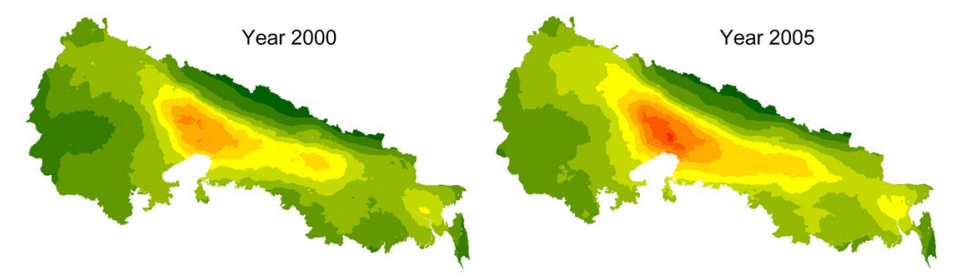

PM 2.5

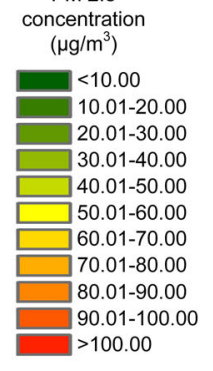

Fig. 7 Global Annual PM2.5 data (micrograms per cubic meter $\left(\mu \mathrm{g} / \mathrm{m}^{3}\right)$ of ground-level fine particulate matter, with dust and sea-salt removed) distribution across the Brick Belt for 4 epochs of time (2000, 2005, 2010 and 2015) at a spatial resolution of 0.01 ${ }^{\circ}$ (data source: https://sedac. ciesin.columbia.edu/data/set/sdei-global-annual-gwr-pm2-5-modis-misr-seawifs-aod). Concentrations of PM2.5 are mapped in classes of 10 ug/m ${ }^{3}$ as illustrated by the key.

converted to more energy efficient, less polluting, Zig-Zag kilns, thus reducing the emission factors of the kilns (Haque et al., 2018). Variations on this basic design have been implemented, including: the Improved Zig-Zag kiln (IZK); natural draught kiln (Zig-Zag ND); and high/induced draught kiln (Zig-Zag HD). The latter two are commonly found in the central region of the Belt covering parts of India and Nepal, and Bangladesh (Maithel et al., 2014, pp. 5-12). Emissions reduction is the main characteristic of the Zig-Zag kiln; fuel consumption can be reduced by up to $40 \%$ (leading to reduced fuel requirement), whilst increasing the quality of bricks produced (PEC, 2018). More specifically $70 \%$ of all emissions are reduced (PEC, 2018). Zig-Zag kilns may not be the most efficient-Hybrid Hoffman and Tunnel kilns are touted as the most-but the costs associated with the improvements are the most affordable and realistic (CCAC, 2017). Traditional kilns can be adapted which reduces further landcover change, necessary for the construction of new kiln clusters; further limiting economic costs and environmental damage. 

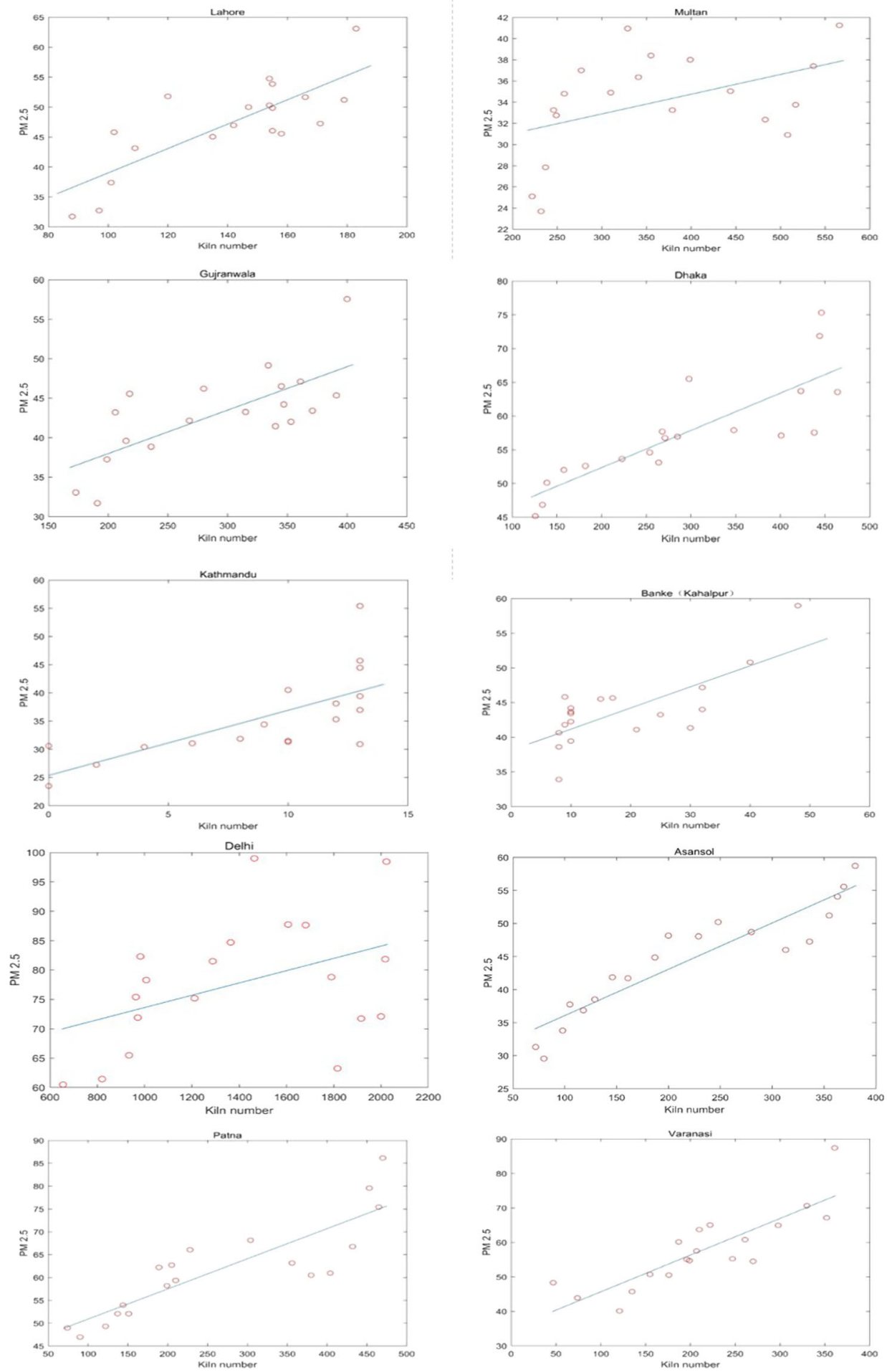

Fig. 8 PM 2.5 concentration vs. Kiln number for those urban areas having the largest number of kilns across the four countries of study. For each of these areas, the city boundaries as determined by GADM data (version 3.6) which maps the administrative areas of all countries, at all levels of subdivision (https://gadm.org/download_country_v3.html) were used to determine the number of kilns present for the period 1998-2016, and this was plotted against the spatially corresponding annual concentrations of PM2.5 $\left(\mu \mathrm{g} / \mathrm{m}^{3}\right)$.

Improvements require investments; however, costs can be recuperated by the reduced volume of raw extractive materials needed for fuel (ADB, 2012). An Asian Development Bank (ABD) project provides credit to brick makers enabling them to improve standards in their current kiln or build new energy-sensitive and sustainable kilns. Overall, the energy efficiency savings are substantial (Larsen, 2016, p. 14). At present, the majority of kiln improvements have occurred in Bangladesh (thus only a portion of the kilns assessed have been improved). These schemes are necessary for the entire Brick Belt. Monitoring and evaluation of these projects could be supported via satellite EO data.

It is clear that social and environmental benefits can be gained by improving traditional brick kilns. According to Larsen (2016, pp. 14-20) the costs and benefits of kiln improvements in 
Bangladesh's Greater Dhaka region suggests that the costs of efficiency improvement are far outweighed by the benefits, which include: reduced operational costs; support for climate change mitigation; limitation of building and vegetation damage; lowering degradation to water and soil; health benefits and a reduction in mortality levels. Thus leading to better working, and living, conditions for all. That said, improvements are beneficial for the environment can lead to short-term cost increases; thus in kilns where debt bondage is already present, there could be further exploitation. To those workers and kiln owners who are on the cusp of using exploitative practices the price of environmental improvement could raise levels of vulnerability to modern slavery.

Consequently, identification of vulnerable workers in kilns where efficiency improvements have been made requires monitoring. Support must be provided by development actors who assist in kiln improvement initiatives to avoid workers being unduly impacted. As kilns adopt these technologies to limit their environmental footprint, those which do not must be investigated for the presence of environmentally and socially harmful practices. Whilst reducing emission levels is vital to limiting their environmental impact, extraction levels must also be addressed and moves toward sustainable brick-materials must take place.

The insight afforded by satellite EO data on the brick kilns in this region illustrates the power of these data in tackling the United Nations SDGs (Burke et al., 2021). Our example and analysis join a range of humanitarian issues that have been shown to benefit from satellite remote sensing data (Lang et al., 2019; Jean et al., 2016; Andries et al., 2018; McDonald et al., 2021). Our focus here has been on SDG Target 8.7, but we acknowledge that the use of satellite data will not be applicable for the measurement of all forms of modern slavery and indeed "sky-high solutions, even smart ones, aren't a cure all" (Scoles, 2019). But we do need to be able to "see" slavery-know where it may be occurring and/or where vulnerability lies. As such, we advocate that an Anti-Slavery Digital Observatory be established. This digital platform will combine novel, non-traditional data streams, including satellite data, to allow for increasingly-sophisticated analyses of modern slavery (Landman, 2019). Although the cost of capturing VHR imagery may be prohibitive for antislavery activists to use extensively, we suggest that partnerships, such as the International Charter Space and Major Disasters (Bessis et al., 2004), may be a way forward. Indeed, the Global Slavery Index reports 24.9 million people are in forced labour, i.e., $62 \%$ of all those estimated to be in modern slavery. This underlines how much antislavery could benefit from the latest satellite technologies for mapping, dating and extracting features of structures and events associated with slavery activity (fishing vessels, logging, mining, etc.). This has potential for immediate global applicability and replication, including reaching areas that may be dangerous, and/or out-ofbounds, such as the areas controlled by ISIS (Al-Dayel et al., 2020), with high levels of temporal up-date. Thus, truly uncovering populations of vulnerable people that are hidden in plain sight.

Slavery is forever evolving across its various forms, and antislavery efforts need to keep up with that dynamism to make meaningful progress toward global emancipation by 2030. The fundamental human right to freedom requires holistic insight and measurement if it is to be successfully defended. In this article, we discuss how using these EO data provides opportunities to address the inherent challenge of capturing fine-scale spatiotemporal patterns in the physical sites that underpin modern slavery. This is sorely needed to facilitate effective, efficient and evidence-based advancement towards SDG 8.7, and its intersecting SDGs. There is now a firm basis for rapid scale-up of this sort of work (Brown et al., 2020; Chen et al., 2020; Estoque, 2020; Jackson,). Future research should focus on fully understanding interdependent and mutually reinforcing relationships at play.

\section{Data availability}

All data are available in the manuscript or the supplementary materials. The underpinning brick kiln mapping and construction data are available by request to the corresponding author DSB.

Received: 4 October 2020; Accepted: 21 April 2021; Published online: 14 May 2021

\section{References}

Agrawak P (2020) Digital platform developed to map non-compliant brick manufacturing units to tackle air pollution. The Logical Indian. https:// thelogicalindian.com/good-to-know/sundarbanshoney26169? infinitescroll=1. Accessed 21 Jan 2021

Al-Dayel N, Mumford A, Bales K (2020) Not yet dead: The establishment and regulation of slavery by the Islamic State. Stud Confl Terror. https://doi.org/ 10.1080/1057610X.2020.1711590

Anti-Slavery International (2017) Forced Labor in the Brick Kiln Sector in India (ASI Report, July 2015). http://www.antislavery.org/wp-content/uploads/ 2017/01/forced-labour-in-brick-kilns-in-india-august-2015-briefing.pdf. Accessed 20 Aug 2019

Andries A et al. (2018) Translation of Earth observation data into sustainable development indicators: an analytical framework. Sustain Dev 27:366-376. https://doi.org/10.1002/sd.1908

Asian Development Bank (ADB) (2012) Bangladesh: financing Brick Kiln Efficiency Improvement Project. Sovereign (Public) Project: 45273-001. Retrieved 23 April, from https://www.adb.org/projects/45273-001/main

Bales K (2012) Disposable people: new slavery in the global economy, 2nd edn. University of California Press, Berkeley

Begum BA, Biswas SK, Hopke PK (2011) Key issues in controlling air pollutants in Dhaka, Bangladesh. Atmos Environ 45(40):7705-7713. https://doi.org/ 10.1016/j.atmosenv.2010.10.022

Berchoux T et al. (2019) Agricultural shocks and drivers of livelihood precariousness across Indian rural communities. Landsc Urban Plan 189:307-319

Bessis JL, Bequignon J, Mahmood A (2004) The International Charter "Space and Major Disasters" initiative. Acta Astronaut 54:183-190

Biswas D et al. (2018) The drivers and impacts of selling soil for brick making in Bangladesh. Environ Manag 62:792-802

Boyd DS et al. (2018) Slavery from Space: demonstrating the role for satellite remote sensing to inform evidence-based action related to UN SDG number 8. ISPRS J Photogramm 142:380-388

Breiman L (2001) Random forests. Mach Learn 45:5-32

Brown C et al. (2020) Investigating the potential of radar interferometry for monitoring rural artisanal cobalt mines in the Democratic Republic of the Congo. Sustainability 12(23):9834. https://doi.org/10.3390/su12239834

Brown D et al. (2019) Modern slavery, environmental degradation and climate change: fisheries, field, forests and factories. Environ Plann E 2:51485E+15

Budhwar R et al. (2003) DNA-protein crosslinks as a biomarker of exposure to solar radiation: a preliminary study in brick-kiln workers. Biomarkers 8:162-166

Burke M et al. (2021) Using satellite imagery to understand and promote sustainable development. Science 371:6535. eabe8628

Chen J et al. (2020) A comprehensive measurement of progress toward local SDGs with geospatial information: methodology and lessons learned. ISPRS Int J Geo-Inf 9(9):522. https://doi.org/10.3390/ijgi9090522

Choi-Fitzpatrick A (2017) What slaveholders think: how contemporary perpetrators rationalize what they do. Columbia University Press

Climate \& Clean Air Coalition (CCAC) (2017) Technical assistance for brick kiln financing in Bangladesh. http://www.ccacoalition.org/en/activity/technicalassistance-brick-kiln-financing-bangladesh. Accessed 23 Apr 2019

Darain KM et al. (2013) Brick manufacturing practice in Bangladesh: a review of energy efficacy and air pollution scenarios. J Hydrol Environ Res 1(1):60-69

Decker Sparks JL et al. (2021) Growing evidence of the interconnections between modern slavery, environmental degradation, and climate change. One Earth https://doi.org/10.1016/j.oneear.2021.01.015

Economic Times (2013) Odisha govt directs removal of brick kilns from river beds. The Indian Times. https://economictimes.indiatimes.com/news/environment/ the-good-earth/odisha-govt-directs-removal-of-brick-kilns-from-river-beds/ articleshow/20785268.cms?from=mdr. Accessed 5 Apr 2019

Estoque R (2020) A review of the sustainability concept and the state of SDG monitoring using remote sensing. Remote Sens 12(11):1770. https://doi.org/ $10.3390 / \mathrm{rs} 12111770$

Foody GM et al. (2019) Earth observation and machine learning to meet Sustainable Development Goal 8.7: mapping sites associated with slavery from Space. Remote Sens 11:266. https://doi.org/10.3390/rs11030266

Friedl MA et al. (2002) Global land cover mapping from MODIS: algorithms and early results. Rem Sens Environ 83(1-2):287-302. https://doi.org/10.1016/ S0034-4257(02)00078-0 
Ganguly S et al. (2010) Land surface phenology from MODIS: Characterization of the Collection 5 global land cover dynamics product. Rem Sens Environ 114 (8):1805-1816

GEFONT (2008) Labor under the Chimney: a study on the brick kilns of Nepal. GEFONT General Federation of Nepalese Trade Unions, Kathmandu Nepal. https://www.gefont.org/assets/upload/downloads/brick_klin_report_2008. pdf. Accessed 20 Aug 2019

Gomes E, Hossain I (2003) Transition from traditional brick manufacturing to more sustainable practices. Energy Sustain Dev 7(2):66-76. https://doi.org/ 10.1016/S0973-0826(08)60356-7

Gray J, Sulla-Menashe D, Friedl MA (2019) User guide to collection 6 MODIS Land Cover Dynamics (MCD21Q2) Product. Land Cover \& Surface Climate Group Boston University, Boston

Guttikunda SK, Begum BA, Wadud Z (2013) Particulate pollution from brick kiln clusters in the Greater Dhaka region, Bangladesh. Air Qual Atmos Health 6 (2):357-365

Gupta A (2015) Bihar to close down brick kilns along the Ganga. Down to Earth. https://www.downtoearth.org.in/news//bihar-to-close-down-brick-kilnsalong-the-ganga-42919. Accessed 3 Apr 2019

Hall $\mathrm{O}$ et al. (2019) Population centroids of the world administrative units from nighttime lights 1992-2013. Sci Data 6:235. https://doi.org/10.1038/s41597019-0250-z

Haque MI et al. (2018) Particulate black carbon and gaseous emission from brick kilns in Greater Dhaka region, Bangladesh. Air Qual Atmos Health 11:925-935. https://doi.org/10.1007/s11869-018-0596-y

Hawksley H, Pradesh A (2014) Why India's Brick Kiln Workers 'Live Like Slaves'. BBC News Asia. http://www.bbc.co.uk/new/world-asia-india-25556965. Accessed 20 Aug 2019

International Labour Office (2005) Unfree labor in Pakistan: work, debt and bondage in brick kilns. ILO, Geneva

International Labour Organisation (2017) Global estimates of modern slavery: forced labor and forced marriage. ILO, Geneva

Jackson B (2020) Remote sensing of fish-processing in the Sundarbans Reserve Forest Bangladesh: an insight into the modern slavery-environment nexus in the coastal fringe Maritime Stud 19:429-444.https://doi.org/10.1007/s40152020-00199-7

Jean $\mathrm{N}$ et al. (2016) Combining satellite imagery and machine learning to predict poverty. Science 353:790-794

Kara S (2014) Bonded labor: tackling the system of slavery in South Asia. Columbia University Press, New York

Khan A, Qureshi AA (2016) Bonded labor in Pakistan. Oxford University Press, Oxford

Khumbar S et al. (2014) Environmental life cycle assessment of traditional bricks in western Maharashtra, India. Energy Procedia 54:260-269. https://doi.org/ 10.1016/j.egypro.2014.07.269

Landman T (Ed.) Code 8.7: Conference Report (2019/02/19-20 New York. United Nations University, New York

Landman T (2018) Out of the shadows: transdisciplinary research on modern slavery. Peace Hum Rights Gov 2:1-15

Landman T (2020) Measuring modern slavery: law, human rights, and new forms of data. Hum Rights Q 42(2):303-331

Landman T, Silverman BW (2019) Globalization and modern slavery. Politics Gov 7(4):275-290

Lang S et al. (2019) Earth observation tools and services to increase the effectiveness of humanitarian assistance. Eur J Remote Sens https://doi.org/ $10.1080 / 22797254.2019 .1684208$

Larsen B (2016) Benefits and costs of brick kilns options for air pollution control in Greater Dhaka. Bangladesh Priorities Project. Copenhagen Consensus Center and BRAC Research and Evaluation Department

Lee $J$ et al. (2021) Landscape of brick manufacturing in Bangladesh: a scalable approach to deep learning for sustainable development. Proc Natl Acad Sci USA 118(17):e2018863118. https://www.pnas.org/content/118/17/e2018863118

Loo YY, Billa L, Singh A (2015) Effect of climate change on seasonal monsoon in Asia and its impact on the variability of monsoon rainfall in Southeast Asia. Geosci Front 6(6):817-823. https://doi.org/10.1016/j.gsf.2014.02.009

Long Y et al. (2017) Accurate object localization in remote sensing images based on convolutional neural networks. IEEE Trans Geosci Remote Sens 55:2486-2498

Lopez A et al. (2012) Pathways to efficiency in the South Asia brickmaking industry. The Carbon War Room, Washington

Loveland TR, Belward AS (1997) The IGBP-DIS global $1 \mathrm{~km}$ land cover data set, DISCover: first results. Int J Remote Sens 18(15):3289-3295. https://doi.org/ $10.1080 / 014311697217099$

Luby SP et al. (2015) Why highly polluting methods are used to manufacture bricks in Bangladesh. Energy Sustain Dev 28:68-74

Lundgren-Kownacki K et al. (2018) Climate change-induced heat risks for migrant populations working at brick kilns in India: a transdisciplinary approach. Int J Biometeorol 62(3):347-358. https://doi.org/10.1007/s00484-017-1476-0
Lutz AF et al. (2014) Consistent increase in High Asia's runoff due to increasing glacier melt and precipitation. Nat Clim Change 4:587-592. https://doi.org/ $10.1038 /$ nclimate2237

Maithel S, Kumar S, Laichandani D (2014) Factsheets about brick kilns in South and South-East Asia. Greentech Knowledge Solutions, New Delhi

McDonald et al. (2021) Satellites can reveal global extent of forced labor in the world's fishing fleet. Proc Natl Acad Sci USA 4(2):181-191

McGrath S, Watson S (2018) Anti-slavery as development: a global politics of rescue. Geoforum 93:22-31

Mellander C et al. (2015) Night-time light data: a good proxy measure for economic activity? PLoS ONE 10:e0139779

Min B (2015) Power and the vote: elections and electricity in the developing world. Cambridge University Press, Cambridge

Misra P et al. (2020) Mapping brick kilns to support environmental impact studies around Delhi using Sentinel-2. ISPRS Int J Geo-Inf 9:544. https://doi.org/ 10.3390/ijgi9090544

Mitra D, Valette D (2017) Brick by brick: environment, human labour \& animal welfare. Brooke, The Donkey Sanctuary, and International Labour Organization (ILO), Geneva

Moda HM et al. (2019) Impacts of climate change on outdoor workers and their safety: some research priorities. Int J Environ Res Public Health 16(18):3458. https://doi.org/10.3390/ijerph16183458

MWFP EPA (2004) Guidelines: brick kiln units. Pakistan. http://www.environment.gov. pk/images/provincialsepasguidelines/I1BBrickKilns.pdf . Accessed 20 Aug 2019

Natarajan $\mathrm{N}$ et al. (2019). Climate change adaptation and precarity across the rural-urban divide in Cambodia: towards a 'climate precarity' approach. Environ Plann E https://doi.org/10.1177/2514848619858155

Nazir U et al. (2020) Kiln-Net: a gated neural network for detection of brick kilns in south Asia. IEEE J Selected Top Appl Earth Observ Remote Sens 13:3251-3262. https://doi.org/10.1109/JSTARS.2020.3001980

Nepal S et al. (2019) A comparative study of stack emissions from straight-line and zigzag brick kilns in Nepal. Atmosphere https://doi.org/10.3390/atmos10030107.

Nilsson M, Griggs D, Visbeck M (2016) Map the interactions between Sustainable Development Goals. Nature 534:320-322

Pakistan Engineering Council (PEC) (2018) Training on construction \& understanding operations of zig-zag brick kilns. PEC Newsl 3, 1-2. https://www. pec.org.pk/downloads/newsletter/PEC\%20Newsletter_2018_Jul_Sep.pdf

Pradhan P et al. (2017) A systematic study of Sustainable Development Goal (SDG) interactions. Earth's Future https://doi.org/10.1002/2017EF000632

Rajarathnam U et al. (2014) Assessment of air pollutant emissions from brick kilns. Atmos Environ 98:549-553

Reyers B, Selig ER (2020) Global targets that reveal the social-ecological interdependencies of sustainable development. Nat Ecol Evol https://doi.org/ 10.1038/s41559-020-1230-6

Sadoff C et al. (2013) Ten fundamental questions for water resources development in the Ganges: myths and realities. Water Policy 15:147-164

Saeed A (2017). Pakistan third largest brick-producing country in South Asia. Bus Rec. https://fp.brecorder.com/2017/05/20170504175631/. Accessed 8 Apr 2019

Schwarz K, Allain J (2020) Tracking the implementation gap. Statelessness Citizensh Rev 2(1):159-166

Sapkota TB et al. (2015) Climate change adaptation, greenhouse gas mitigation and economic profitability of conservation agriculture: some examples from cereal systems of Indo-Gangetic Plains. J Integr Agric 14(8):1524-1533. https://doi.org/10.1016/S2095-3119(15)61093-0

Save the Children (2007) The small hands of slavery. Save the Children Fund, London

Scoles S (2019) Researchers spy signs of slavery from space. Science https://doi.org/ 10.1126/science.aax 0751

Shah A (2006) The Labour of Love: seasonal migration from Jharkhand to the brick kilns of other states in India. Contributions to Indian Sociology (n.s.) 40. Sage Publications, New Delhi; Thousand Oaks; London

Shrestha A et al. (2013). Groundwater extraction: implications on local water security in peri-urban Kathmandu, Nepal. Peri Urban Water Security Discussion Paper Series, 7, SaciWATERs

Silverman BW (2020) Multiple systems analysis for the quantification of modern slavery: classical and bayesian approaches. J R Stat Soc Ser A https://doi.org/ $10.1111 /$ rssa. 12505

Sulla-Menashe D, Friedl MA (2018) User Guide to Collection 6 Land Cover (MCD12Q1 and MCD12C1) Product. Land Cover \& Surface Climate Group Boston University, Boston

Tickler D et al(2018) Modern slavery and the race to fish Nat Commun 9:4643. https://doi.org/10.1038/s41467-018-07118-9

United Nations (UN) (2016) Transforming our World: the 2030 Agenda for Sustainable Development, A/RES/70/1. United Nations General Assembly, New York

Verbesselt J, Zeileis A, Herold M (2012) Near real-time disturbance detection using satellite image time series. Rem Sens Environ 123:98-108

Walk Free (2016) The Global Slavery Index, 3rd edn. Minderoo Foundation, Perth 
Walk Free Foundation and International Labour Organization (2018) The Global Slavery Index 2018. The Global Slavery Index

Xiao P et al. (2014) Dynamics of urban density in China: estimations based on DMSP/OLS nighttime light data. IEEE JSTARS 7:4266-4275

Yunong T et al. (2019) Apple detection during different growth stages in orchards using the improved YOLO-V3 model. Comput Electron Agric 157:417-426

Zhu Z, Woodcock CE (2012) Object-based cloud and cloud shadow detection in Landsat imagery. Remote Sens Environ 118:83-94

\section{Acknowledgements}

We warmly thank all the members of the Rights Lab team, not listed as coauthors of the study, for their incredible support. We also are very grateful to Airbus Defence and Space for free access to Pléiades data and Google for the opportunity afforded by their platform. This work was supported by grants to GMF and DSB from UK's Engineering and Physical Sciences Research Council [grant numbers EP/R512849/1 and EP/T001569/1]; the British Academy Visiting Fellowships Programme, under the UK Government's Rutherford Fund, which supported XL's work at the University of Nottingham; the University of Nottingham for Beacon of Research Excellence funding to the Rights Lab; and the Strategic Priority Research Program of Chinese Academy of Sciences (XDA2003030201) to FL.

\section{Author contributions}

$\mathrm{DSB}, \mathrm{KB}$ and GMF conceived the study. BP and XL performed the analyses. DSB, BP and $\mathrm{XL}$ wrote the manuscript with contributions from all authors.

\section{Competing interests}

The authors declare no competing interests.

\section{Additional information}

Correspondence and requests for materials should be addressed to D.S.B.

Reprints and permission information is available at http://www.nature.com/reprints

Publisher's note Springer Nature remains neutral with regard to jurisdictional claims in published maps and institutional affiliations.

(c) (i) Open Access This article is licensed under a Creative Commons BY Attribution 4.0 International License, which permits use, sharing, adaptation, distribution and reproduction in any medium or format, as long as you give appropriate credit to the original author(s) and the source, provide a link to the Creative Commons license, and indicate if changes were made. The images or other third party material in this article are included in the article's Creative Commons license, unless indicated otherwise in a credit line to the material. If material is not included in the article's Creative Commons license and your intended use is not permitted by statutory regulation or exceeds the permitted use, you will need to obtain permission directly from the copyright holder. To view a copy of this license, visit http://creativecommons.org/ licenses/by/4.0/.

(c) The Author(s) 2021 